um, stürze dann das Gefäss schnell über die Glasplatte. Auf diese Weise rinnt das Nelkenöl gewissermaassen dampfförmig auf die Silberlösung; nach Verlauf von $\frac{1}{4}$ Stunde ist der Spiegel fertig und zwar ohne Flecken. Im Grossen lässt sich das Nelkenöl viel einfacher dampfförmig anbringen; es ist aber stets darauf zu sehen, dass dasselbe nicht tropfenweise mit der Silberlösung in Berübrung kommt, weil in diesem Falle sogleich braune Flecken entstehen. Der Vorsicht halber habe ich das über die Glasplatte gestiurzte Gefäss ebenfalls mit einem Rande umgeben.

\title{
Notiz über den Aether als Betäubungsmittel und über Prüfung des Aethers;
}

von

H. Wa aken roder.

Herr P. T. Meissner, ehemals Professor der Chemic in Wien, jetzt Eisenhüttenpraktikant in Zöptau in Mähren, hat in einem Anruf an die Aerzte (oder vielmehr an die sämmtlichen Herren Aerzte von Europa, Asien, Afrika, Amerika, Oceanien u. s. w.) hinsichtlich der von ibm sogenannten Ae therfrage auf sein schon vor längerer Zeil publicirtes "System der Heilkunde, aus den allgemeinsten Naturgesetzen gefolgert, aufmerksam gemacht (Deulsche allg. Zeit. No. 90. 31. März 1847). Herr Professor M e issner erinnert in diesem lakonischen Anruf u. A. daran, dass die auffallend verschiedenen Wirkungen, welche bei Anwendung des Schwefeläthers oft bemerkt worden, wahrscheinlich irrthümlich der verschiedenen Organisation der behandelten Individuen zugeschrieben würden. Er halte sich iuberzeugt, dass wohl in den meisten Fällen eine verschiedeneB eschaffenheit des Aethers die Ursache so abweichender Erscheinungen gewesen sei; denn der käulliche Aether enthalte sehr oft schweflige Säure und fast immer Alkohol und Weinöl. Nun sei aber bekannt, 
dass die schweflige Säure äusserst leicht zum Husten reize und Kopfleiden hinterlasse. Der Alkohol wirke dem Aether entgegengesetzt, und das Weinöl erhitze und möchte wohl der Stoff sein, den man slundenlang nach der Operation noch am Exhalat der Patienten durch das Geruchsorgan wahrnimmt, während absolut reiner Aether in kürzester Zeit aus dem warmen Organismus entweiche.

Es werde also vor allen Dingen nothwendig sein, künftighin die Experimente mit reinem Aether vorzunehmen, um allen Unfällen zu entgehen, und endlich auszumitteln, ob die Betäubung nur allein vom Aether, und nicht etwa auch vom Weinöl und Alkohol abhängig sei, oder auf welche Weise dieselbe durch diese Beimischung modificirt werde.

Diese, wie mich dünkt, beachtenswerthen Anmahnungen des Herrn Professors Meissner veranlassen mich zur Mittheilung einiger Versuche und Beobachtungen, welche schon vor einigen Jahren bei der Darstellung und Prüfung des Aethers von mir gemacht wurden. Diese Versuche lenken die Aufmerksamkeit vornehmlich auf ein Zersetzungsproduct des Alkohols, das man für Essigsäure angesehen haben mag.

Wird ganz reiner Aether mit etwa einem gleichen Volumen concentrirter Schwefelsäure gemischt, so entsteht bekanntlich eine farblose Flüssigkeit, welche auch bei längerem Stehen keine Farbe annimmt. Wird Wasser hinzugefügt, so scheidet sich der Aether wieder farblos ab.

Häufig jedoch färbt sich nach meinen Beobachtungen das Gemisch von Schwefelsäure und Aether beim Stehen ganz schwach gelblich, und das mit käuflichem Aether nicht selten ziemlich stark bräunlichgelb.

Der Grund dieser Färbung kann nur gesucht werden in der verschiedenen Reinheit des Aethers. Zunächst können aber Ald ehyd und Wein öl diejenigen Beimengungen sein, welche jene Färbung veranlassen. Vom Aldehyd wenigstens ist sie mit Zuverlässigkeit bekannt.

Um eine bessere Einsicht in dieses abweichende Verhalten des Aethers zu erlangen, wurde bei einer zum 
Behufe didaktischer Demonstration ausgefuhrten Darstellung des Aethers im Herbst 1844 unler Mitwirkung des damaligen Herrn Assistenten Volland eine besondere Rücksicht darauf genommen.

Es wurden nämlich $360 \mathrm{Grm}$. gute englische Schwefelsäure und $240 \mathrm{Grm}$. Alkohol von 0,84. spec. Gew. bei mittlerer Temperatur vermischt und unter beständigem Zufluss von demselben Alkohol $1 / 1 \frac{1}{2}$ Stunden regelmassig uber Oelflammen gekocht. Das Destillat zeigte kaum eine Wasserschicht. Das stets bei demselben Volumen erhaltene Säuregemisch hatte nur eine dunkle Weinfarbe angenommen. Als es noch vierStunden lang für sich erhitzt wurde, gab es noch ziemlich viel ätherisches Destillat mit einer starken Wasserschicht, und erschien dann bei durchfallendem Lichte mit dunkelbrauner, bei auffallendem Lichte mit grünlicher Farbe. Aus der Verschiedenheit der Destillate und des Säuregemisches erhellet also, dass in dem ersten, weingeisthaltigen Destillate möglichst wenig von den Producten enthalten sein konnte, welche die Bildung des Aethers gewöhnlich begleiten.

Es wurde daher auch das erste Destillat, welches nur schwach sauer reagirte, für sich gelassen und mit Kalkwasser und elwas Aetzkalilauge geschüttelt. Der abgesonderte rohe Aether betrug etwa $340 \mathrm{Grm}$., war farblos tand reagirte neutral. Bei der Prüfung desselben mit Schwefelsäure entstand eine gelbliche, nach längerem Stehen bräunliche, ziemlich dunkle Färbung der Flüssigkeit.

Beider Rectification dieses rohen Aethers aus einer Retorte über einer allmälig vergrösserten Oelflamme wurden sechs Fractionen gemacht und jede geprüf.

1) Gewicht 33 Grm. Sp. G. $=0,724$ bei mittlerer Temperalur (von $18^{\circ}$ bis $20^{\circ} \mathrm{C}$. und direct gefunden durch Abwägen des aräometrischen Probeglases, des Wassers and des Aethers bei gleicher Temperatur and gleichem Luftdruck, und daher behaftet mit dem möglichst grössten Fehler von $\pm 1 \frac{1}{3}$ Einheiten in der dritten Decimalstelle). Mit etwa einem gleichen Volumen conc. Schwefelsäure ver- 
mischt, entstand eine kaum gelbliche Flüssigkeit, deren Farbe auch nach 24 Stunden dieselbe blieb.

2) Gewicht 85 Grm. Spec. Gew. = 0,725. Concentrirte Schwefelsäure bewirkte, selbst nach 24 Stunden keine Färbung.

3) Gewicht 60 Grm. Spec. Gew. = 0,729. Die Prüfung mit Schwefelsäure hatte denselben Erfolg.

4) Gewicht 31 Grm, Spec. Gew. $=0,766$. Steigender Siedepunct. Schwefelsäure gab eine gelbliche, nach Verlauf von 24 Stunden etwas dunkler gefärbte Flüssigkeit.

5) Gewicht $30 \mathrm{Grm}$. Spec. Gew. $=0,821$. Steigender Siedepunct. Die gelbliche Färbung mit Schwefelsäure war stärker.

6) Gewicht $23 \mathrm{Grm}$. Spec. Gew. $=0,848$. Das Destillat roch wenig nach Aether, mehr nach Weingeist. Die Reaction der concentrirten Schwefelsäure war noch stärker und die Probefliussigkeit wurde bräunlich und binnen 24 Stunden noch dunkler.

Der Ruickstand in der Retorte betrug etwa $60 \mathrm{Grm}$., zeigte ein spec. Gewicht von 0,986 , und reagirte sauer. Chlorbaryum bewirkte eine schwache Fällung und oxalsaures Kali nur eine geringe Trübung. Es schwamm nur wenig Oel auf der Flüssigkeit und in der Ruhe wurde die Flüssigkeit klar und farblos. Mit einem gleichen Volumen reinen Aethers und dann mit concentrirter Schwefelsäure gemischt, entstand zwar eine gelbliche Fluissigkeit, die aber weniger gefärbt war, als die gemischten Fluissigkeiten bei 5 , und 6 .

Das durch stärkere Erhitzung des Aethergemisches erhaltene Destillat, ebenfalls mit Kalkwasser und Aetzkali geschuittelt, sonderte einen Aether ab, der bei gelinder Hitze etwa bis zur Hälfte rectificirt wurde. Zufällige Umstände verhinderten eine genaue Vergleichung dieses rectific. Aethers mit dem erstern, und nur die Färbung desselben mit conc. Schwefelsäure konnte constatirt werden. Der noch stark nach Aether riechende klare Ruickstand in der Retorte hinterliess, in einer offenen Schale $\frac{1}{4}$ bis $\frac{1}{2}$ Stunde lang 
der freiwilligen Verdunstung überlassen, eine saure, mit kleinen Oeltropfen vermischte Flüssigkeit.

Aus diesen Versuchen folgt: 1) dass der die Bräunung der Schwefelsäure bewirkende Körper sich auch in demjenigen rohen Aether befindet, der ke in e Wasserschicht und wenig oder gar keine schweflige Säure und folglich auch wenig Weinöl enthält; 2) dass derselbe in dem in gelindester Wärme rectificirten Aether nur wenig oder gar nicht, am meisten aber in dem bei erhöheter Temperatur rectificirten Aether und zwar reichlicher enthalten ist, als in dem weinöligen Rückstande.

Demnach ist zu vermuthen, dass dieser Körper A ld ehy d, oder Aldehydsäure, oder ein anderes ähnliches Zersetzungsproduct des Alkohols ist. Dafür spricht auch der Umstand, dass der abdestillirte Ruickstand in der Retorte jederzeit wieder sauer geworden ist, ohne eine bedeutende Menge von Schwefelsäure aus zersetztem ätherschwefelsaurem Aetherol zu enthalten.

Von dem Aldehyd dürte man aber wohl eine nachtheilige Einwirkung auf das Nervensystem voraussetzen, wenn eine grosse Menge des Aetherdampfs zum Zwecke der Betäubung eingeathmet wird.

Das im Aether vorhandene Weinöl kann möglicherweise auch nachtheilig wirken. Indessen zeigt sich der Gehalt an Weinöl in dem käuflichen Aether jetzt meistens sehr gering bei der Verdunstung des Aethers ohne künstliche Wärme, wobei das Weinöl ziemlich vollständig zurückbleibt. Die bekannte Probe der freiwilligen Verdunstung des Aethers auf einem Uhrglase weiset in dem hinterbleibenden wässerigen Rückstande auch das Weinöl nach.

Weingeist enthält der käufliche, durch ein geringes spec. Gewicht ausgezeichnete Aether jetzt in der Regel auch nur wenig, insofern die vermehrte Löslichkeit des Aethers in Wasser einen Maassstab dafür abgiebt. Werden 20 Volumen eines solchen käuflichen, übrigens vortrefflichen Aethers und eben so viel reines Wasser in einer graduirten Glasröhre mit einander geschüttelt, so ver- 
schwinden meistens nur 2 Volumina des Aethers, also nicht mehr, als wenn absoluter Aether mit Wasser geschüttelt wird. Ein solcher Aether kann aber dennoch nicht vorzüglich sein, wenn er nämlich, wie ich mehrmals gefunden habe, mit Schwefelsäure sich gelb oder bräunlich färbt, auf dem Uhrschälchen mit Hinterlassung von ziemlich viel Wasser verdunstet und nach Verlöschen der Flamme des angezündeten Aethers einen stets sauren Ruickstand hinterlässt. Ein von uns selbst rectificirter Aether, der beim Schütteln mit Wasser $\frac{3}{20}$ Vol. verlor, also dem gewöhnlichen Schlusse nach noch ein wenig Alkohol enthielt, verdunstete mit nur einer Spur von Wasserriickstand, zeigte mit Schwefelsäure $\mathbf{k}$ a u m eine Spur gelblicher Färbung und hinterliess eine völlig neutrale Flüssigkeit, als er in einer tiefen Porcellanschale bis etwa zur Hälfte verbrannt und dann die Flamme durch Aufdecken einer Schale erstickt wurde.

Die bei dem Halbverbrennen des Aethers entstehende Säure scheint Essigsäure zu sein, deren Bildung mit der Gegenwart von Aldehyd im Zusammenhang gedacht werden kann. Auch das freiwillige Sauerwerden manches käuflichen Aethers wird in Beziehung stehen zu dem Stoffe, der die Schwefelsäure bräunt. Da dieses Selbstsäuern bei dem Aether, der mit Schwefelsäure ein farbloses oder nur schwach gelbliches Gemisch giebt, niemals, wie ich glaube, statt findet, so scheint mir hier ein Causalnexus ausser Zweifel.

Die Verunreinigung des Aethers mit schwefliger Säure, an welche HerrProf. M e is s n er ausdrücklich erinnert, würde offenbar von den gefährlichsten Folgen sein für die Einathmung des Aetherdampfes. Indessen findet man sie doch jetzt bei dem Aether wenigstens höchst selten, der in Mitteldeutschland fabrikmässig dargestellt wird. Wenn das mit dem Aether benetzte dunkelblaue Lackmuspapier beim Liegen an der Luft nicht roth wird, so kann man ziem. lich sicher die Abwesenheit der schwefligen Säure behaupten. Das mit dem Aether geschüttelte Wasser und der wässerige Rückstand von der freiwilligen Verdunstung

Arch. d. Pharm. C. Bds. 2. Hif. 
des Aethers, so wie auch der Rückstand des halbverbrannten Aethers gestatten die weiteren Reactionen auf schweflige Säure.

Dass ein Gehalt an Fuselöl in dem zur Darstellung des Aethers benutzten Weingeist von Einfluss auf den Aether sein kann, ist nicht so unwahrscheinlich, als man meistens anzunehmen geneigt ist, da dieser Einfluss bis dahin vielleicht nicht genau genug beachtet worden ist.

\section{Dinige Bemerkungen uiber die Darstellung des absoluten Alkohols; von \\ H. Wacken roder.}

Der reine absolute Alkohol ist für analytische Untersuchungen von zu grossem Werthe, als dass nicht ein sorgfältiges Studium der Methoden der Darstellung desselben ein grosses Interesse gewähren sollte. Die nachstehenden Bemerkungen könneu daher vielleicht einige Nachsicht erlangen, obwohl sie einen längst bekannten Gegenstand belreffen. Sie sind das Ergebniss mehrfacher Versuche, die zum Theil zum Behufe des Unterrichts angestellt wurden. Bei den zuletzt vorgenommenen Versuchen ist insbesondere Herr Assistent L a d wi g sehr hülfreich und thätig gewesen.

Die Entwässerung des Weingeistes durch ätzenden Kalk scheint mir nicht allein die leichteste und billigste Melhode der Darstellung des absoluten Alkohols zu sein, sondern auch einen völlig reinen Alkohol zu liefern, wenn alle Umstände gehörig beachtet werden. Meine Bemerkungen werden sich daher nur auf diese übrigens hinlänglich bekannte Methode beziehen.

Eine Tubulatretorte von etwa 4 Pfd. Wasser Raumesinhalt wird bis zur Hälfte mit Aelzkalk in Stïcken von der Grösse einer Haselnuss angefüllt. Man giesst nun völlig fuselfreien Weingeist von 90 Proc. (den man jetzt auch 